\title{
Regional variation in the effect of schooling on people's incomes in Poland
}

\begin{abstract}
The analysis, based on a Polish national sample from 2006, aims to cast light on the regional variation in the effect of education on incomes. Building on the conceptual framework developed in the theory of human capital we investigate to what extent pay-offs for human capital differ across detailed administrative districts in Poland. By incorporating contextual characteristics, we examine how micro- and macro-level factors shape labour market outcomes. Our findings provide further support for the hypothesis that there is much regional variation in the influence of education on incomes, which suggests that there are better and worse places for the development of a meritocratic distribution of incomes. It appears that education pays more highly in more economically-developed regions, marked by a higher rate of occupational activity.
\end{abstract}

Keywords

Incomes $\cdot$ returns from education $\cdot \mathrm{PISA} \cdot$ regional variation $\bullet$ meritocracy

(C) University of Warsaw - Faculty of Geography and Regional Studies

\author{
Henryk Domański ${ }^{1}$ \\ Artur Pokropek ${ }^{2}$ \\ 'Polish Academy of Sciences \\ Institute of Philosophy and Sociology \\ e-mail: hdomansk@ifispan.waw.pl \\ 2Polish Academy of Sciences \\ Institute of Philosophy and Sociology \\ e-mail: apokropek@ifispan.waw.pl \\ Received: 25 April 2014 \\ Accepted: 8 October 2014
}

Introduction

Empirical research on the returns of education has been a topic of interest since the 1970s. Regarding Western societies, studies have repeatedly documented a modest, at worst, association between these variables. Consistent with the functional or institutional imperative, sociologists following this line of research have focused on the consequences of this pattern for modernization, labour markets, and the operation of companies (Featherman \& Hauser 1978; Neckerman \& Torche 2007; Sorensen 2007). In recent years, motivated by the availability of new data sets and advances in theories of structural changes following the post-communist transformation, there has been renewed interest in understanding the determinants of income distribution. A number of empirical studies have investigated the determinants of incomes in post-communist countries and communist China in order to diagnose the process of marketization and understand how human capital is allocated in the specific institutional context (Gerber \& Hout 1998; Wu \& Xie 2003; Domański 2008; for overview see Heyns 2005).

The debates on market transition are mainly focused on whether or not the importance of human capital characteristics has increased. Despite these substantial contributions, the research has largely provided an overall picture of the gradual replacement of the state by the market, as a principal agent of social stratification, but offer little purchase on explaining the mechanisms underlying this logic. The purpose of this paper is to add a regional dimension to these findings. We investigate the relationship between education and income across the regional districts in Poland, in order to determine to what extent the distribution of incomes arises from interaction between individual attributes and the local contexts. By incorporating contextual characteristics, we examine how micro- and macro-level factors shape labour market outcomes.

\section{Theoretical background and previous research}

A widespread and influential view is that the relationship between incomes and education is part of the process of social stratification. The functional theory of stratification explains that a relatively high gradation of income by level of educational investment is necessary to provide incentives for individual effort (Treiman 1970). Based on this assumption, a close association between rewards and individual productivity, as reflected in education, is among the indicators of economic effectiveness, modernization, and meritocracy. In sociology this development is often expressed as the replacement of ascription by achievement values (Barone \& Schizerotto 2011). Building on a similar argumentation, labour economists focus on heterogeneity in productivity as a consequence of the variation in investments in skill acquisition (Becker 1975).

The impact of market reform in Poland on processes of socio-economic attainment, the privatisation of the economy and the replacement of the planned economy by the market, should result in increasing returns to human capital. Apart from China, the impact of market reform on processes of socio-economic attainment has been most intensively studied in Poland. Indeed, from the 1990s onwards Poland faced a steady increase in returns to university education - although the rise to meritocracy had already begun in the 1980s, it continued relentlessly until the 2000s (Domański 2008). This tendency has been paralleled 
by growing benefits to managers and professionals. This was in apparent agreement with another corollary of the market transition theory that, following a shift of market allocation, the category of professionals - who are leading 'contributors' in building modern structures - will experience net gains over those categories that occupy less strategic positions (Nee 1989). It was argued that the logic is that capitalist transition should enhance the rewards accrued by this category due to their high level of education, expertise and skills, not to mention their social capital. Moreover, privatization of the economy distinguished between workers belonging to the private and state sectors, with the incomes advantages of education being more pronounced in the private sector, appearing to dictate a more rational and efficient allocation of rewards based on workers' productivity (Domański 2008).

Certainly, as the system of meritocracy has developed, not all Poles have benefited equally from the economic transition. The literature has been inconclusive so far on whether workers with marketable skills grasped new opportunities across all regions of Poland in the same way. Our main purpose here is to link macrolevel socio-economic transitions and individuals' incomes by introducing regional divisions as an intermediate process.

\section{Hypotheses}

An adequate understanding of what shapes incomes inequality in present-day Poland must therefore take into account the local variation. In order to gain a deeper insight into this question we will determine to what extent the association between education and incomes depends on place of living, defined in terms of regions. Given the continuing increase in returns to education and marketization in Poland, our question concerns the function of the local setting: e.g. whether educational credentials pay better in big or small cities, in the periphery or in the centre, in rich or in poor regions, etc.

Building on the insight that rewards are often tied to place of residence, studies show that regions can stratify even identically qualified individuals. In the United States, income inequality across states appeared to be positively correlated with returns to education, in that individual returns increased with inequality (Mayer 2001). This suggests that returns to human capital can be affected by regional variation. Previous studies on market transition in post-communist countries missed the link between the operation of regional labour markets and individuals' labour market outcomes. To date, discussions on regional variation have not included a systematic analysis of the Polish case. Using survey data we attempt to determine whether incomes accruing to education vary from region to region on the basis of contextual characteristics. We test three hypotheses concerning the operation of labour markets on a regional scale with respect to openness of social structure, level of economic development and availability of the labour force.

The first hypothesis relates the effect of education on incomes to the openness of the social structure. It can be assumed that meritocracy (taken to be expressed primarily by educational attainment) should perform better in more permeable structures. We measure openness in terms of marital homogamy, defined by the relationship between the spouses' occupational categories, with the implication that if people more often marry outside their socio-occupational category the social barriers are less rigid (McPherson et al. 2001). With reference to regional differentiation it can be contended that in more 'open' regions employers are more ready to reward employees according to human capital this tendency may be additionally enhanced by social support for the application of this rule by the community. In contrast, there may be more impediments to the implementation of meritocratic distribution in more rigid social structures.
The second hypothesis concerns the impact of economic development obtained by a percentage of the active labour force. To the extent that greater economic development provides more incentives to reward individuals according to human capital (since it amplifies productivity), employers in more developed regions are more likely to recruit and reward employees according to merits. Firms that fail to do so - those that allocate wages inefficiently - should lose out to the competition. Competition increases with the growing size of the labour force.

The third hypothesis posits that a greater population density within a region increases the supply of the labour force, which exerts pressure for rewarding individuals according to meritocratic rules. Hence, a higher effect of education on incomes may also arise from higher competition which allows for the quality sorting of employees with varying abilities and attributes. It seems likely that - controlling for economic development - in more populated areas, rewards are more closely related to individual productivity and human capital.

\section{Data}

The data come from the Polish edition of the international project PISA 2006 (The Programme for International Student Assessment), which is conducted every three years (beginning from 2000) in about 60 countries on national random samples. PISA is the biggest international educational research project aimed at measuring the knowledge and skills (mathematics, literacy and science) crucial for proper functioning in contemporary society.

The basic target population in PISA is 15-year-old pupils (in some countries also including other age cohorts). As well as the cognitive test measuring abilities and skills, some additional information is collected. In each country pupils fill in a questionnaire including, among others, items on socio-economic status of parents and family living conditions. In some countries (including Poland) a questionnaire is also completed by the parents themselves, including detailed background variables on incomes, education, living conditions, etc. In our analysis we use this part of the data.

The Polish survey drew a multistage sample with primary sampling units of 179 secondary schools (stratified according to the number of 15-year-old students). In the second stage 35 pupils and their parents were selected from within the sampled schools. In schools with less than 35 students of 15 years old, all students were chosen. This sampling design resulted in a representative, random sample of 15 -year-old pupils, along with their parents, consisting of 5423 observations (families = pupils + parents). The response rate in the Polish sample was $90 \%$.

Most importantly for our purposes, this data set links individuals to place of residence to the extent that the sampled secondary schools are located in administrative districts ('gmina' in Polish, with the exception of Warsaw, where secondary schools are associated with quarters). This permitted characteristics defined on the regional level (such as population density, etc.) to be assigned to individuals.

\section{Variables}

To assess the influence of regional variation on the relationship between education and incomes we will regress family incomes on schooling and regional location, identified with schools, alongside characteristics of the regions. All individual level variables come from the questionnaire completed by the parents. The dependent variable, household income, is based on retrospective reporting of all sources of household income. Respondents reported mean income (over the last three months) in Polish 'zlotys' ( 1 zloty equals approximately 4 Euros in 2009). 
MISCELLANEA GEOGRAPHICA - REGIONAL STUDIES ON DEVELOPMENT

Vol. $19 \cdot$ No. 1 - pp. 12-18 - 2015 - ISSN: 2084-6118 • DOI: 10.2478/mgrsd-2014-0029

Table 1. Descriptive statistics of the variables

\begin{tabular}{|c|c|c|c|c|c|}
\hline Variables & N & Mean & SD & Minimum & Maximum \\
\hline Household's income & 4566 & 1711.39 & 1241.64 & 600.00 & 5000.00 \\
\hline Father's years of schooling (centred) & 5417 & 0.00 & 2.29 & -4.95 & 6.05 \\
\hline Mother's years of schooling (centred) & 5417 & 0.00 & 2.56 & -5.54 & 6.05 \\
\hline Villages & 179 & 0.30 & 0.46 & 0.00 & 1.00 \\
\hline Number of people per 1 km ${ }^{*} 100$ & 177 & 10.79 & 9.33 & 0.15 & 32.91 \\
\hline Percentage of employed in region (centred) & 177 & 0.00 & 3.22 & -15.19 & 8.11 \\
\hline Percentage of homogamous couples & 179 & 28.64 & 11.18 & 6.90 & 65.38 \\
\hline Years of schooling - mean in region (centred) & 179 & 0.00 & 1.12 & -1.90 & 5.25 \\
\hline
\end{tabular}

The human capital variable is education. Because we are using household incomes, it is reasonable to employ the educational attainment of both parents. The mother's and father's education are measured in terms of years of completed education centred to the mean of the whole sample, i.e. 1 indicates that the respondent studied one year longer as compared to the mean, -1 that he/she studied one year less than the mean, etc.

The respondents are linked to the regions ('gmina'/city quarter) by the schools of their children. In testifying the influence of the region-level variables on the relationship between education and incomes we will build multi-level models to differentiate the individual-level from the regional-level variance. To test the effect of regional differentiation on openness of social structure we derived a scale of marital homogamy according to the mothers' and fathers' occupational categories. They are represented in terms of the Erikson-Goldthorpe measure of social class referring to EGP (Erikson \& Goldthorpe 1992). The detailed version of the EGP was collapsed to six basic categories: (i) higher professionals and managers, (ii) routine non-manual, including lower managers, semi-professionals, clerical workers, service and sales, (iii) owners, (iv) manual supervisors and skilled workers, (v) unskilled workers, (vi) farmers and agricultural labourers. We established the degree of occupational homogamy for each of the 179 regions as the percentages of marriages involving husbands and wives of the same EGP class.

Following hypotheses 2 and 3 , we have constructed two measures of regional variation using information from the Local Data Bank (2006). The level of economic development is operationalized by the percentage of occupationally active inhabitants of a productive age, centred to the sample mean hence, respondents living in areas with an average percentage (across regions) were assigned with 0 ; positive and negative values of this measure indicate, respectively, a higher or lower percentage relative to the mean. The third region-level variable - population density - is operationalized by the number of inhabitants per square kilometre of the region, multiplied by 100 , to make the interpretation easier.

The control variables include mean education in the region and place of residence. Mean education level is a contextual characteristic of a region that may be associated with income, regardless of the levels of education of individuals in that region. For each region this is the mean of years of schooling completed, centred to the mean. With regards to place of residence we use a dummy variable that captures the distinction between village and city dwellers, with village dwellers coded 1 , otherwise 0 . Table 1 presents the descriptive statistics for the variables used in our analysis.

\section{Method}

We used a 2-level model where 1-level variables are individual characteristics of the household, and 2-level variables are characteristics of the place of residence (Raudenbush \& Bryk 2002; Skrondal \& Rabe-Hesketh 2008). In matrix form the model is specified as:

$y_{i j}=\mathbf{x}_{i j}^{\prime} \boldsymbol{\beta}+\mathbf{z}_{i j}^{\prime} \zeta_{j}+\varepsilon_{i j}$

where subscripts $i$ and $j$ represent, respectively, households and regions (identified by the schools). The covariate vector $\mathbf{x}_{i j}^{\prime}=\left(1, x_{1 i j}, x_{2 i j} \ldots x_{n i j}\right)$ denotes the covariates for fixed effects. $\boldsymbol{\beta}^{\prime}=\left(\beta_{0}, \beta_{1}, \ldots \beta_{n}\right)$ includes both households and second-level parameters, as well as cross-level interaction parameters. Vector $\mathbf{Z}_{i j}^{\prime}=\left(1, z_{1 j}\right)$ denotes the independent variables for random effects $\zeta_{\mathrm{j}}=\left(\zeta_{0 j}, \zeta_{1 j}\right)$, and $\varepsilon_{i j}$ denotes the error component.

Our analysis consists of two steps. Firstly, we estimate a series of models for regional exposure to the effect of education on incomes, testing the specific expectations from the preceding sections. We then turn to assess which (if either) of the effects - regarding regional characteristics - "dominate" in influencing incomes. The second step permits conclusions about whether regional variation plays a pronounced role in shaping the distribution of incomes according to human capital.

\section{Findings: regional variation}

In the first column of Table 2 we report one-level regression estimates for the simplest model of incomes determination. This is a baseline model with education of husbands and wives included as predictors, which does not take into account regional variation of the relationship between education and income. Both predictors have significant effects on incomes. As expected, one additional year of schooling increases income, although the father's level of education brings much better returns. For fathers, the rate of return to education stands at 162.9 zlotys, while for the mothers, 109.6 zlotys.

These results confirm the well-known fact that more highly educated individuals may enjoy higher returns. However, it would be premature to conclude from these results that the labour market utilizes human resources efficiently. The question arises as to what extent the relationship between education and incomes is caused by regional variation. To examine this issue we applied a multilevel approach. We begin with the empty model which includes only the intercept and random effects for the dependent variable. The empty model provides useful information about how much variation in the outcome lies within and between regions. The intercept value identifies mean 
Table 2. Single level and multilevel regression models for household income in Poland 2006

\begin{tabular}{|c|c|c|c|c|c|c|}
\hline & \multirow{2}{*}{$\begin{array}{l}\text { One- } \\
\text { level }\end{array}$} & \multicolumn{5}{|c|}{ Multilevel models: } \\
\hline & & Empty & $\begin{array}{l}\text { Random } \\
\text { Intercept }\end{array}$ & $\begin{array}{l}\text { Random } \\
\text { Slope } 1\end{array}$ & $\begin{array}{l}\text { Random } \\
\text { Slope } 2\end{array}$ & $\begin{array}{l}\text { Random } \\
\text { Slope } 3\end{array}$ \\
\hline \multicolumn{7}{|l|}{ Fixed effects: } \\
\hline Father's years of schooling & $162.9^{* *}$ & & $141.0^{* *}$ & $135.2^{* *}$ & $137.7^{* *}$ & $134.5^{* *}$ \\
\hline Mother's years of schooling & $109.6^{* *}$ & & $99.0^{* *}$ & $99.9^{* *}$ & $98.1^{* *}$ & $99.4^{* *}$ \\
\hline Intercept & $1750.5^{\star \star}$ & $1774.5^{\star \star}$ & $1770.3^{* *}$ & $1743.4^{* *}$ & $1746.0^{* *}$ & $1737.0^{\star *}$ \\
\hline \multicolumn{7}{|l|}{ Random effects: } \\
\hline Intercept & & 559.4 & 301.6 & 281.5 & 285.9 & 282.2 \\
\hline Slope (father's years of schooling) & & & & 75.0 & & 83.9 \\
\hline Slope (mother's years of schooling) & & & & & 61.1 & 66.9 \\
\hline $\begin{array}{l}\text { Corr(father's years of schooling- } \\
\text { intercept) }\end{array}$ & & & & 0.72 & & 0.50 \\
\hline $\begin{array}{l}\text { Corr(mother's years of schooling- } \\
\text { intercept) }\end{array}$ & & & & & 0.73 & 0.35 \\
\hline $\begin{array}{c}\text { Corr(father's-mother's years of } \\
\text { schooling) }\end{array}$ & & & & & & -0.45 \\
\hline Residuals & & 1134.8 & 1069.7 & 1059.3 & 1060.9 & 1052.6 \\
\hline \multicolumn{7}{|l|}{ Measures of fit: } \\
\hline Log likelihood & -38478.3 & -38780.0 & -38425.1 & -38403.1 & -38407.3 & -38394.6 \\
\hline Reference model & & Mean & Empty & RI & RS1 & RS2 \\
\hline LR test: $\mathrm{Chi}^{2}$ & & 471.43 & 693.05 & 44.25 & 35.66 & 16.82 \\
\hline LR test: $p$ & & 0.0000 & 0.0000 & 0.0000 & 0.0000 & 0.0008 \\
\hline $\mathrm{N}$ & 4566 & 4566 & 4566 & 4566 & 4566 & 4566 \\
\hline
\end{tabular}

(RI: Random Intercept; RS1: Random Slope 1, etc.)

${ }^{*} p \leq 0.05{ }^{* *} p \leq 0.01$

income and random effects - household level and region level variances.

Results show that most of the variation in income is at the household level (1134.8), although a substantial proportion is between regions (559.4). The interclass correlation (Rho), which represents the proportion of variance in income between regions related to overall variation, is 0.2 , which means that place of residence explains 20 percent of families' income. One may conclude that incomes are rather strongly associated with the residential settlement of households. In fact, as shown in Table 2, allowing incomes to vary across regions significantly improves the fit of the models. The value of the LR test (471.43) is statistically significant, meaning that the hypothesis about the lack of regional variation can be rejected.

Regarding the crucial question, concerning regional variation in returns to human capital, we turn to the following four models. The random intercept model assumes that the region-specific regression lines are parallel and place of residence only makes a difference to level of income. It shows that the common slopes for father's and mother's years of schooling, shared by all regions, are estimated as 141.0 and 99.0 and the mean intercept as 1770.3. The random slope models relax the assumption that the region regression lines are parallel by introducing random region-specific slopes. The hypothesis related to the RS models corresponds with the prediction that the place of residence influences not only the levels of incomes but also the rules of its distribution. Thus, the models Random Slope 1 and Random Slope 2 allow the parameters of (respectively) father's and mother's years of schooling to vary across regions, and the model Random Slope 3 allows both effects to vary.

According to fit statistics the RS3 model performs best (LR = 16.82, Log likelihood = 38394.6), which supports the thesis about regional differentiation of the relationship between education and income. These results for fathers' and mother's education are depicted graphically in Figures 1 and 2. In each figure, the bold solid line represents the population-averaged regression line across all 179 regions. The thinner lines represent region-specific regressions for the regions. Perhaps the most notable feature of the figures is the considerable variability between intercepts for different regions. It can be observed that men and women 
with the same years of schooling strongly differ in income level depending on place of residence. The variability of the slopes is also clear, although slightly less pronounced. It can be noted that there is a tendency for some regions to have substantially steeper slopes (this is displayed a bit more strongly amongst women). More detailed analyses (not presented here) revealed that these steeper slopes represent the big cities and more wealthy regions, for parents whose children study in private schools. Broadly, the results confirm the expectations that getting paid according to educational level depends on geographical location.

One can draw three conclusions from Table 2. Firstly, the estimated effects of years of schooling provided by the one-level model are higher than the effects established in the multilevel models. In the latter case the averages of the fathers' slopes vary between 134.5-141.0, and the mothers' slopes between 98.1-99.9. In one-level model these estimates are 162.9 and 109.6. This overestimation illustrates the typical failure of the one-level model to represent the nesting of individuals within the regions-grouping variable, which can be controlled in the multilevel models.

Secondly, estimates of the correlation between the intercept and slopes, produced by multilevel models, enable us to determine in which regions the returns to education are higher and in which lower: whether they are higher in high-income or in low-income regions. These estimates are presented in the middle panel of Tables 2 and 3 as corr(father's years of schooling * intercept) and corr(mother's years of schooling * intercept).

As can be seen, the correlations of the slopes and intercept are positive. They were estimated as 0.50 amongst men and 0.35 amongst women, which indicates that education pays better in the higher-income regions.

The final remark concerns a comparison of returns to women and men. According to expectations, household income is definitely more strongly influenced by men's education. One year of the father's schooling contributes approximately 40 percent more towards the household income than the mother's. This finding provides support for the thesis that, despite the growing occupational activity of women, men still bring more to the household budget. It is noteworthy that higher returns to education for men, which may be treated as greater "conversion power", indicate that the situation of women is far worse than that of men, contrary to the optimistic scenario of some market transition theories (Nee \& Matthews 1996). Moreover, the negative correlation between the slopes of the father's and mother's education $(-0.45)$ suggests that the growing role of meritocratic distribution of incomes amongst husbands is tending to weaken its role amongst wives. It seems that the more efficient use of educational assets by men is paralleled by a decrease in its incentive role for women. This may mean that they are more engaged in family life, in the roles of mothers and wives whether willingly, or perhaps due to commitments to traditional customs and norms.

\section{Regional characteristics}

Having estimated the variability of the returns to education across regions, we now seek to build an explanatory model to account for this variability. Following our hypotheses, we seek to understand why in some regions the association between years of schooling and incomes is stronger than in others. Table 3 displays the results. The consecutive models give estimates for both individual and region-level effects of population density, percentage of the active labour force, and openness of social structure.

The results reported in Table 3 provide support only for the hypothesis concerning the positive effect of the percentage of

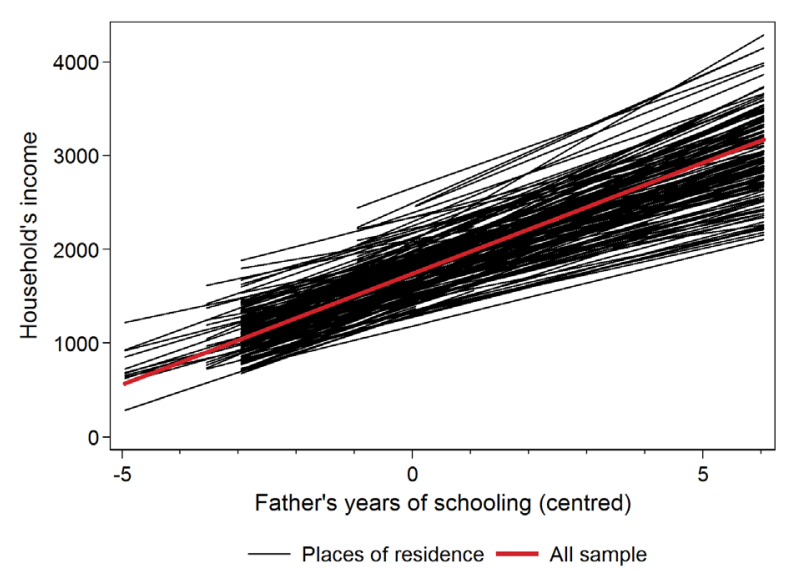

Figure 1. Regression lines for the father's years of schooling

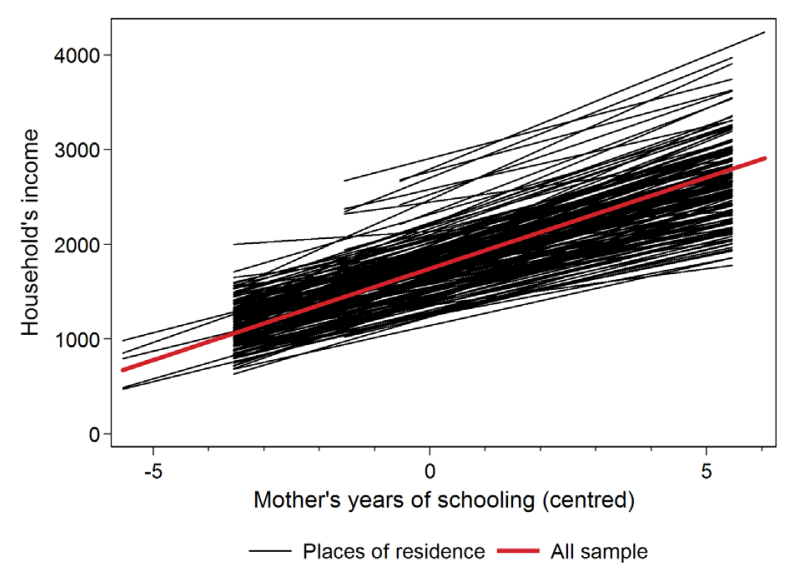

Figure 2. Regression lines for the mother's years of schooling

active labour force in the region, taken as a proxy of economic development. As expected, inhabitants of more developed regions enjoy higher incomes - in the range of 18.8-22.7 zlotys advantage for one additional percentage of the labour force. Most importantly, there is a tendency for regions with a higher percentage of working population to have larger returns. A one percent increase of the active labour force yields 9.0-10.6 zlotys increase in returns to the father's education (this interaction is not statistically significant for the mother's). Assuming that higher occupational activity reflects higher economic development, competition for jobs and modernization, this may imply that investments in human capital in such places bring more benefits, and meritocratic distribution works more efficiently there.

Less straightforward are the effects of population density and openness of the social structure measured by the occupational homogamy of spouses. Regarding population density (represented by number of inhabitants per $\mathrm{km}^{2}$ ) it can be seen that its addition to the equation means that years of schooling eliminates the positive effect of this factor. Testing various models we also established that population density did not significantly affect returns to education - this effect is not included in the models presented in Table 3.

As regards marital homogamy our findings reveal that it remains a significant net determinant of incomes; in regions with higher homogamy there is a positive association with incomes. Concerning the effect of homogamy and the association between education and incomes, returns to education turn out to be higher 
Table 3. Effects of regional characteristics on incomes

\begin{tabular}{|c|c|c|c|c|}
\hline & \multicolumn{4}{|c|}{ Multilevel models (with contextual variables): } \\
\hline & Random Slope 4 & Random Slope 5 & Random Slope 6 & Random Slope 7 \\
\hline \multicolumn{5}{|l|}{ Fixed effects: } \\
\hline Father's years of schooling & $132.3^{* *}$ & $129.6^{* *}$ & $71.4^{* *}$ & $89.8^{* *}$ \\
\hline Mother's years of schooling & $97.7^{* *}$ & $99.5^{\star *}$ & $99.1^{* *}$ & $93.0^{* *}$ \\
\hline Intercept & $1655.9^{* *}$ & $1661.7^{* *}$ & $1508.2^{* *}$ & $1627.7^{* *}$ \\
\hline \multicolumn{5}{|l|}{ Contextual variables: } \\
\hline Village & $-139.2^{* *}$ & $-122.7^{*}$ & $-145.1^{*}$ & -87.5 \\
\hline Number of inhabitants per $\mathrm{km}^{2} * 100$ & $12.1^{* *}$ & $11.0^{*}$ & $10.3^{\star *}$ & 3.6 \\
\hline Percentage of employed & & $18.8^{*}$ & $22.7^{* *}$ & $18.9^{*}$ \\
\hline Marital homogamy & & & $5.8^{*}$ & $4.0^{*}$ \\
\hline Mean years of schooling & & & & $170.5^{\star *}$ \\
\hline $\begin{array}{c}\text { Father's years of schooling*Percentage of } \\
\text { employed }\end{array}$ & & $9.0^{* *}$ & $10.6^{\star *}$ & $9.4^{* *}$ \\
\hline Father's years of schooling ${ }^{\star}$ Marital homogamy & & & $2.0^{* *}$ & 1.0 \\
\hline \multicolumn{5}{|l|}{ Random effects: } \\
\hline Intercept & 218.4 & 210.4 & 201.3 & 170.4 \\
\hline Slope (father's years of schooling) & 86.8 & 81.3 & 76.0 & 77.4 \\
\hline Slope (mother's years of schooling) & 60.3 & 60.2 & 58.9 & 56.0 \\
\hline corr(father's years of schooling- intercept) & 0.60 & 0.55 & 0.49 & 0.41 \\
\hline corr(mother's years of schooling- intercept) & 0.40 & 0.41 & 0.42 & 0.26 \\
\hline corr(father's-mother's years of schooling) & -0.41 & -0.46 & -0.52 & -0.50 \\
\hline Residuals & 1055.3 & 1057.8 & 1058.3 & 155.1 \\
\hline \multicolumn{5}{|l|}{ Measures of fit: } \\
\hline Log-likelihood & -37854.6 & -37162.2 & -37157.2 & -37138.4 \\
\hline Reference model & RS3 & RS4 & RS5 & RS6 \\
\hline LR test: $\mathrm{Chi}^{2}$ & 54.91 & 7.95 & 10.10 & 37.50 \\
\hline LR test: $p$ & 0.0000 & 0.0188 & 0.0064 & 0.0000 \\
\hline $\mathrm{N}$ & 4504 & 4421 & 4421 & 4421 \\
\hline
\end{tabular}

(RI: Random Intercept; RS1: Random Slope 1, etc.)

${ }^{*} p \leq 0.05{ }^{* *} p \leq 0.01$

in more rigid social structures (a 2.0 increase in the RS6 model). However, the net effect of regional homogamy disappears after controlling for mean years of schooling (see model RS7), leading to the conclusion that the positive effect of more permeable structures is a spurious association, which is mostly caused by the fact that regional variation in homogamy is related to mean years of schooling.

\section{Conclusion}

Previous studies on market transition in post-communist societies have missed the link between macro-level regional differences and individuals' incomes. This analysis, based on Polish data, aimed to cast light on the regional variation in the effect of education on incomes. This was to determine to what extent pay-offs for human capital differ across detailed administrative districts in Poland. In fact, our findings confirm the popular wisdom about regional variation in returns to education, which suggests that there are better and worse places for the development of meritocratic distribution of incomes.

Which regions offer higher advantages and which lower? It appears that education pays more in more economicallydeveloped regions, marked with a higher rate of occupational 
activity. One may suspect that, on the one hand, such places foster a higher motivation to reward individuals according to human capital in more efficiently operating markets. On the other hand, in more developed regions there is higher competition for wages and jobs, and employers have higher demands - all these factors encourage and enforce the rules of rewarding individuals by merit. Marketization may not lead immediately to the application of these rules, but with time it may be expected that managerial staff in more developed areas reorient decisions regarding pay schedules toward the market criteria.

It appears that returns to education are much higher for men. This shows that household income is more strongly affected by men's years of schooling than by women's. One extra year of men's schooling increases the household income by 40 percent more, compared to women. Not surprisingly, this confirms the dominance of the husband's contribution to the household budget - men continue to provide their families with money despite the increasing occupational activity of women and administrative measures aimed at decreasing differences between women and men. Our results indicate that this difference may be attributed to the more important role of men's 'productive assets'. The negative correlation between returns to education amongst husbands and wives suggests that the more efficient use of a husband's educational capital may be an impediment to the development of this association in the case of wives.

\section{References}

Barone, C \& Schizzerotto, A 2011, 'Career mobility, education, and intergenerational reproduction in five European societies', European Societies, vol. 13, no. 3, pp. 331-345.

Becker, GS 1975, 'Human capital, 1964', National Bureau for Economic Research, New York

Domański, H 2008, 'Merytokracja w zasadach dystrybucj wynagrodzeń w latach 1982-2005 (Meritocracy and distribution of incomes in 1982-2005)' in Zmiany stratyfikacji społecznej w Polsce (Changes in Social Stratification in Poland), eds H Domański, IFiS Publishers, Warszawa, pp. 153-180.

Erikson, R \& Goldthorpe, JH 1992, The constant flux: A study of class mobility in industrial societies, Oxford University Press, USA.

Featherman, DL \& Hauser, RM 1978, 'Opportunity and change', in Studies in Population, Academic Press. New York NY United States 1978.

Gerber, TP \& Hout, M 1998, 'More shock than therapy: market transition, employment, and income in Russia, 1991-1995 1', American Journal of Sociology, vol. 104, no. 1, pp.1-50.

Heyns, B 2005, 'Emerging inequalities in central and Eastern Europe', Annual Review of Sociology, vol. 31, pp. 163-197.

Local Data Bank, 2006, Avaiable from: <http://stat.gov.pl/bdlen/> [04.04.2009].

Mayer, SE 2001, 'How did the Increase in economic inequality between 1970 and 1990 affect children's educational attainment? 1', American Journal of Sociology, vol. 107, no. 1 , pp. 1-32.
McPherson, M, Smith-Lovin, L \& Cook, JM 2001, 'Birds of a feather: Homophily in social networks', Annual Review of Sociology, vol. 27, pp. 415-444.

Neckerman, KM \& Torche, F 2007, 'Inequality: causes and consequences', Annu. Rev. Sociol., vol. 33, pp. 335-357.

Nee, V 1989, 'A theory of market transition: From redistribution to markets in state socialism', American Sociological Review, vol. 54, no. 5, pp. 663-681.

Nee, V \& Matthews, R 1996, 'Market transition and societal transformation in reforming state socialism', Annual Review of Sociology, vol. 22, pp. 401-435.

Rabe-Hesketh, S \& Skrondal, A 2008, Multilevel and longitudinal modeling using Stata, STATA press.

Raudenbush, SW \& Bryk, AS 2002, Hierarchical linear models: Applications and data analysis methods, Sage.

Sørensen, JB 2007, 'Organizational diversity, labor markets, and wage inequality', American Behavioral Scientist, vol. 50, no. 5 , pp. 659-676.

Treiman, DJ 1970, 'Industrialization and Social Stratification*', Sociological Inquiry, vol. 40, no. 2, pp. 207-234.

$\mathrm{Wu}, \mathrm{X} \&$ Xie, Y 2003, 'Does the market pay off? Earnings returns to education in urban China', American Sociological Review, vol. 68 , no. 5 , pp. $425-442$. 